\title{
Personal Hygiene Berhubungan dengan Keberadaan Telur Ascaris lumbricoides : Studi pada Kuku Pengrajin Batu Bata
}

\author{
Personal Hygiene Related to Ascaris lumbricoides Eggs Existency : A Study of Brick Craftsmen's \\ Nails
}

\author{
Nurtika Afi Wijayanti ${ }^{1}$, Kanti Ratnaningrum ${ }^{2 *}$, Ika Dyah Kurniati ${ }^{3}$ \\ ${ }^{1}$ Program Studi S1 Kedokteran, Fakultas Kedokteran, Universitas Muhammadiyah Semarang \\ ${ }^{2}$ Bagian Parasitologi, Fakultas Kedokteran, Universitas Muhammadiyah Semarang \\ ${ }^{3}$ Bagian Mikrobiologi, Fakultas Kedokteran, Universitas Muhammadiyah Semarang \\ *Penulis Korespondensi. Kanti Ratnaningrum. Email: kantiratna@ymail.com \\ Telepon: +6285727878161
}

\begin{abstract}
ABSTRAK
Pendahuluan: Prevalensi infeksi Ascaris lumbricoides menempati urutan tertinggi dibandingkan dengan infeksi Soiltransmitted Helminths (STH) lain. Hygiene dan sanitasi yang kurang baik menjadi faktor penyebab terjadinya infeksi cacing termasuk askariasis. Tanah, debu, air, sayuran, tangan, dan kuku jari dapat berkontribusi sebagai media transmisi telur cacing. Pengrajin batu bata merupakan salah satu pekerjaan yang berhubungan erat dengan tanah dan air dimana sebagian proses pembuatannya dilakukan secara manual menggunakan tangan. Beberapa metode digunakan untuk identifikasi telur Ascaris lumbricoides dan beberapa studi menyatakan adanya temuan telur cacing pada kelompok pekerja yang kontak erat dengan tanah maupun air. Penelitian ini bertujuan untuk mengetahui hubungan personal hygiene dan sanitasi lingkungan tempat kerja dengan keberadaan telur Ascaris lumbricoides pada kuku pengrajin batu bata.

Metode: Penelitian ini merupakan studi deskriptif analitik dengan pendekatan cross-sectional. Besar sampel dihitung dengan rumus Lemeshow dengan teknik purposive sampling. Sampel merupakan pengrajin batu bata yang berlokasi di Desa Sengonbugel, Kecamatan Mayong, Kabupaten Jepara, Provinsi Jawa Tengah. Pemilihan sampel berdasarkan kriteria inklusi dan eksklusi. Pemeriksaan kuku menggunakan metode sedimentasi. Analisis data menggunakan uji $C h i$ Square. Hasil: Sebanyak 40 subyek penelitian menunjukkan bahwa sebagian besar memiliki personal hygiene baik $(82.5 \%)$ dan sanitasi lingkungan tempat kerja baik (62.5\%). Terdapat hubungan yang bermakna antara personal hygiene dengan keberadaan telur Ascaris lumbricoides pada kuku pengrajin batu bata $(\mathrm{p}=0.002 ; \mathrm{PR}=2,5)$ sedangkan sanitasi lingkungan tempat kerja tidak bermakna $(\mathrm{p}=0,545)$.

Kesimpulan: Personal hygiene berhubungan dengan keberadaan telur Ascaris lumbricoides. Prevalensi keberadaan telur Ascaris lumbricoides pada kuku pengrajin batu bata meningkat 2,5 kali lebih tinggi pada personal hygiene yang buruk.
\end{abstract}

Kata kunci: personal hygiene, telur, Ascaris lumbricoides, kuku, pengrajin batu bata

\begin{abstract}
Introduction: Prevalence of Ascaris lumbricoides infection ranks the highest compared to the other Soil-transmitted Helminths (STH) infections. Ascaris lumbricoides is the cause of ascariasis. Hygiene and poor sanitation are the risk factors of worm infections including ascariasis. Soil, dust, water, vegetables, hands and fingernails can contribute as transmission media of worm eggs. Brick craftsman is one of jobs that is closely related to soil and water because the manufacturing process is done manually by hand. Several methods are used to identify eggs of Ascaris lumbricoides and several studies reveal the findings of worm eggs in groups of workers who had closed contact with soil and water. This study aims to determine the relationship between personal hygiene and workplace environmental sanitation with Ascaris lumbricoides eggs existency on brick craftsmen nails.

Method: This research was an analytical descriptive study with cross-sectional approach. Sample size was determined based on Lemeshow formula with purposive sampling technique. The research sample was brick craftsman located in Sengonbugel Village, Mayong District, Jepara Regency, Central Java Province. Sample selection was based on inclusion and exclusion criteria. Examination of nails used sedimentation method. Data was analyzed by Chi Square test.

Result: Data from 40 samples showed that most of them have a good personal hygiene (82,5\%) and good workplace sanitation (62,5\%). The analyze of the relationship between personal hygiene with Ascaris lumbricoides eggs existency on brick craftsmen nails showed p-value $=0,002$ with prevalence ratio $(P R)=2,5$ meanwhile the relationship between
\end{abstract}


workplace environmental sanitation with Ascaris lumbricoides eggsexistency on brick craftsmen nails showed p-value $=0,545$.

Conclusion: Personal hygiene is related to presence of Ascaris lumbricoides eggs. The prevalence of Ascaris lumbricoides eggs existency on brick craftsmen nails is 2,5 times higher on poor personal hygiene.

Keywords: personal hygiene, worm eggs, Ascaris lumbricoides, brick craftsmen nails

\section{PENDAHULUAN}

Ascaris lumbricoides merupakan penyebab penyakit cacingan yang paling dominan di daerah tropis maupun subtropis. ${ }^{1}$ Ascaris lumbricoides merupakan nematoda kategori Soil-Transmitted Helminths (STH). ${ }^{2}$ Prevalensi infeksi Ascaris lumbricoides menempati urutan tertinggi dibandingkan infeksi STH lain. ${ }^{1}$ Transmisi infeksi cacing dapat terjadi melalui tanah, debu, air, sayuran, tangan, dan kuku jari. ${ }^{3,4}$ Jenis pekerjaan yang banyak melakukan kontak dengan tanah memiliki risiko infeksi cacing lebih tinggi. ${ }^{5}$ Jenis pekerjaan itu meliputi pengrajin batu bata, petani, tukang sampah, pengrajin gerabah, pengrajin genteng dan lain-lain. ${ }^{6}$

Diagnosis infeksi cacing dapat dilakukan melalui pemeriksaan feses namun pemeriksaan kuku juga dapat digunakan sebagai identifikasi keberadaan telur cacing ${ }^{7}$ mengingat kuku merupakan salah satu media transmisi infeksi cacing. ${ }^{3,4}$ Beberapa metode pemeriksaan telur cacing yang digunakan untuk memeriksa kuku meliputi metode sedimentasi, ${ }^{8}$ metode floatasi (pengapungan), dan metode stoll. ${ }^{9}$ Beberapa studi telah melaporkan adanya telur Ascaris lumbricoides pada kuku komunitas pekerja seperti peternak, ${ }^{7,10}$ pengrajin genteng, ${ }^{11}$ nelayan, ${ }^{12}$ kuli angkut tanah, ${ }^{13}$ pengrajin batu bata di Gianyar, Bali ${ }^{14}$ dan di Semarang. ${ }^{15}$

Beberapa faktor yang mempengaruhi kejadian askariasis meliputi pengetahuan, kepemilikan jamban, ${ }^{16}$ perilaku cuci tangan, ${ }^{16,17}$ umur, perilaku, dan pendapatan perkapita. $^{18}$ Adanya potensi risiko penyakit askariasis pada pengrajin batu bata dan masih terbatasnya penelitian yang mengkaji faktor yang berhubungan dengan infeksi Ascaris lumbricoides melatarbelakangi dilakukannya penelitian ini. Penelitian ini bertujuan untuk mengetahui hubungan personal hygiene dan sanitasi lingkungan tempat kerja dengan keberadaan telur Ascaris lumbricoides pada kuku pengrajin batu bata.

\section{METODE}

Penelitian ini merupakan penelitian deskriptif analitik dengan pendekatan crosssectional. Besar sampel ditentukan berdasarkan rumus Lemeshow dengan purposive sampling. Sampel merupakan pengrajin batu bata yang berlokasi di Desa Sengonbugel, Kecamatan Mayong, Kabupaten Jepara, Provinsi Jawa Tengah. Kriteri yang dimasukkan dalam penelitian ini meliputi pengrajin yang mempunyai kuku tangan panjang/ melewati lapisan kulit dan memproduksi batu bata secara manual. Pengrajin dengan kebiasaan BAB tidak menggunakan jamban dan pengrajin yang lokasi kerjanya tidak memiliki sarana pembuangan sampah dan saluran pembuangan air limbah (SPAL) dieksklusikan. Data penelitian menggunakan data primer berupa wawancara kuesioner. Identifikasi telur Ascaris lumbricoides dilakukan dengan melakukan pemeriksaan kuku menggunakan metode sedimentasi di Laboratorium Fakultas Kedokteran Universitas Muhammadiyah Semarang (Unimus). Analisis data menggunakan uji Chi Square. Penelitian ini sudah melalui kaji etik dengan diterbitkannya ethical clearence dari Komite Etik Penelitian Kesehatan Fakultas Kedokteran (KEPK FK) Universitas Muhammadiyah Semarang No.010/FK/2021.

\section{HASIL DAN PEMBAHASAN}

\section{Hasil}


Subjek penelitian sebanyak 40 orang pekerja batu bata yang kemudian dianalisis dan didapatkan informasi bahwa sebagian besar pengrajin batu bata berjenis kelamin laki-laki (87.5\%), dengan personal hygiene baik sebesar 33 orang $(82.5 \%)$, sanitasi lingkungan tempat kerja baik sebesar 25 orang $(62.5 \%)$, dan sebagian besar pengrajin tidak ditemukan telur Ascaris lumbricoides pada kuku sebesar 37 orang (92.5\%) pada tabel 1 .

Tabel 1. Karakteristik pengrajin batu bata

\begin{tabular}{lc}
\hline \multicolumn{1}{c}{ Karakteristik } & $\begin{array}{c}\text { Frekuensi } \\
(\%)\end{array}$ \\
\hline Jenis kelamin & $35(87.5)$ \\
Laki-laki & $5(12.5)$ \\
Perempuan & \\
\hline Personal hygiene & $33(82.5)$ \\
Baik & $2(5.0)$ \\
Cukup & $5(12.5)$ \\
$\quad$ Kurang & \\
\hline Sanitasi lingkungan tempat kerja & $25(62.5)$ \\
Baik & $15(37.5)$ \\
Buruk & \\
\hline Telur Ascaris lumbricoides & $3(7.5)$ \\
Ada & $37(92.5)$ \\
Tidak ada &
\end{tabular}

Tabel 2. Analisis hubungan personal hygiene dan sanitasi lingkungan tempat kerja dengan keberadaan telur Ascaris lumbricoides pada kuku

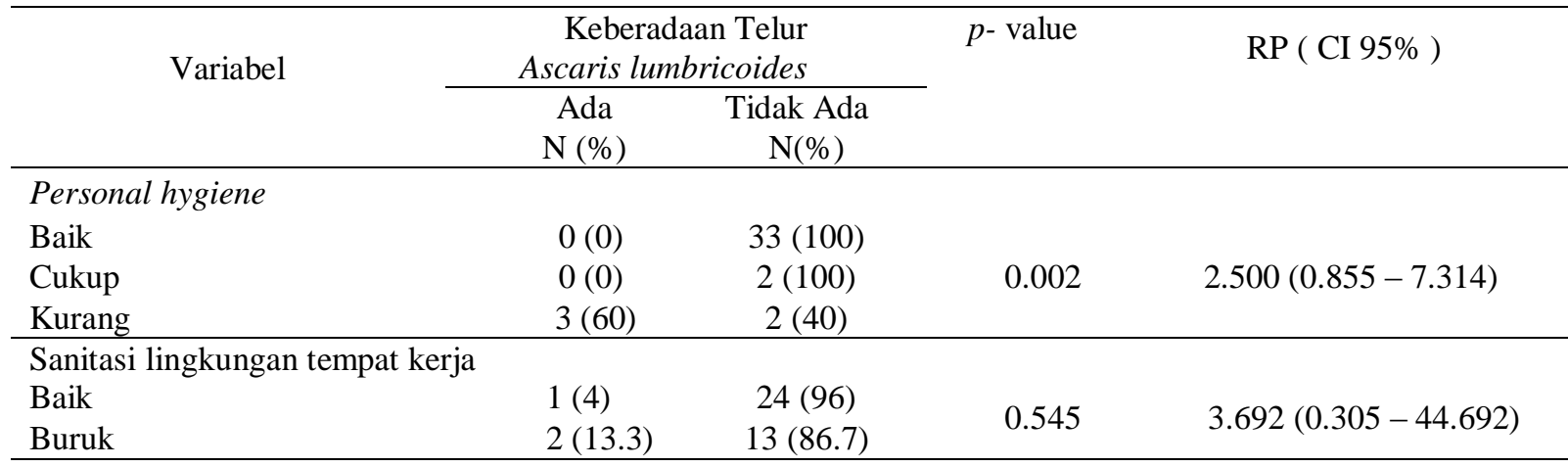

Tabel 2 menunjukkan bahwa terdapat hubungan yang bermakna antara personal hygiene dengan keberadaan telur Ascaris lumbricoides pada kuku pengrajin batu bata dengan prevalensi keberadaan telur Ascaris lumbricoides pada kuku pengrajin batu bata meningkat 2,5 kali lebih tinggi pada personal hygiene yang buruk dibandingkan personal hygiene baik \& cukup. Nilai p-value pada variabel sanitasi lingkungan tempat kerja menunjukkan bahwa tidak terdapat hubungan antara sanitasi lingkungan tempat kerja dengan keberadaan telur Ascaris lumbricoides pada kuku pengrajin batu bata 


\section{Pembahasan}

Penelitian ini menunjukkan bahwa terdapat hubungan antara personal hygiene dengan keberadaan telur Ascaris lumbricoides pada kuku pengrajin batu bata dengan prevalensi keberadaan telur Ascaris lumbricoides pada kuku pengrajin batu bata meningkat 2,5 kali lebih tinggi pada personal hygiene yang buruk dibandingkan personal hygiene baik \& cukup. Beberapa penelitian sebelumnya juga memperoleh hasil serupa namun dilakukan pada sampel siswa sekolah dasar (SD). Penelitian tersebut menyatakan bahwa terdapat hubungan bermakna antara personal hygiene dengan keberadaan telur cacing STH (cacing tambang, Ascaris lumbricoides, Trichuris trichiura) pada kuku. ${ }^{19}$ Penelitian lain yang juga dilakukan di lingkungan SD menerangkan bahwa kebiasaan mencuci tangan dan membersihkan kuku yang termasuk kategori personal hygiene berhubungan dengan kontaminasi telur cacing pada kuku. ${ }^{20}$

Penelitian-penelitian

sebelumnya menyatakan hasil yang beragam perihal personal hygiene. Terdapat penelitian yang menyatakan bahwa ada hubungan antara personal hygiene dengan kejadian infeksi kecacingan pada petugas sampah di Wilayah Kerja BLH Kota Yogyakarta ${ }^{5}$ namun ada pula yang mengemukakan hasil yang berbeda seperti pada penelitian yang dilakukan Desa Karanggeneng Boyolali yaitu tidak ditemukan pengaruh variabel cuci tangan terhadap kejadian cacingan (acsariasis) pada pengrajin batu bata, begitu pula dengan variabel pengetahuan dan kepemilikan jamban. ${ }^{16}$

Ketersediaan sabun juga sangat penting karena mencuci tangan yang benar tidak hanya sekedar membasahi tangan dengan air mengalir tetapi juga memakai sabun. ${ }^{21}$ Mencuci tangan menggunakan sabun dapat lebih efektif dalam membersihkan kotoran dan telur cacing yang menempel pada permukaan kulit, kuku serta jari-jari tangan. ${ }^{9}$ Penelitian sebelumnya membuktikan bahwa tempat cuci tangan yang tidak layak dimana tidak tersedianya air mengalir dan sabun cuci tangan dapat mempengaruhi kejadian infeksi cacing seseorang. ${ }^{22}$

Hasil analisis pada penelitian ini juga menunjukkan tidak adanya hubungan antara sanitasi lingkungan tempat kerja dengan keberadaan telur Ascaris lumbricoides pada kuku perngrajin batu bata. Sama halnya dengan hasil penelitian yang menyatakan bahwa sanitasi lingkungan berupa ketersediaan air bersih tidak berhubungan dengan infestasi cacing STH. Air yang digunakan pada penelitian tersebut adalah sebagian berasal dari air sumur. ${ }^{6}$

Analisis variabel sanitasi lingkungan tempat kerja pada penelitian ini tidak berhubungan dengan keberadaan telur Ascaris lumbricoides pada kuku pengrajin batu bata dapat disebabkan oleh seluruh sampel pengrajin batu bata di Desa Sengonbugel menggunakan sumber air yang berasal dari sumur di lokasi kerja untuk mencuci tangan dimana air tersebut dialirkan melalui selang sehingga pengrajin batu bata menggunakan air mengalir untuk mencuci tangan. Hasil observasi dan wawancara juga didapatkan sebagian pengrajin batu bata menyediakan sabun untuk cuci tangan di lingkungan kerja. Sebagian pengrajin batu bata bermukim dekat dengan lokasi kerja dan mengulang kegiatan cuci tangan menggunakan sabun sepulang dari lokasi kerja. Hal ini menunjukkan bahwa loksi kerja pembuatan batu bata di Desa Sengonbugel, Kecamatan Mayong, Kabupaten Jepara, Provinsi Jawa Tengah memiliki sanititasi lingkungan kerja yang baik.

Penelitian ini juga memiliki kesamaan dengan hasil penelitian Nurfalaq bahwa sanitasi lingkungan berupa ketersediaan air bersih tidak berhubungan dengan infestasi cacing STH dimana air yang digunakan pada penelitian tersebut adalah sebagian berasal dari air sumur. ${ }^{6}$ Pengrajin batu bata di Desa Sengonbugel juga menggunakan sumber air yang berasal dari sumur di tempat kerja untuk mencuci tangan namun air sumur tersebut ditampung di sebuah toler kemudian dialirkan melalui selang sehingga pengrajin batu bata 
tetap bisa menggunakan air mengalir untuk mencuci tangan.

\section{KESIMPULAN DAN SARAN}

\section{Kesimpulan}

Personal hygiene berhubungan dengan keberadaan telur Ascaris lumbricoides sedangkan sanitasi lingkungan tempat kerja tidak berhubungan dengan keberadaan telur Ascaris lumbricoides pada kuku pengrajin batu bata, Desa Sengonbugel, Kecamatan Mayong, Kabupaten Jepara. Prevalensi ditemukannya telur Ascaris lumbricoides pada kuku pengrajin batu bata 2,5 kali lebih tinggi pada kelompok dengan personal hygiene yang buruk/kurang.

\section{Saran}

Perlu dilakukan penelitian serupa dengan menambah sampel pemeriksaan pada feses untuk pemeriksaan telur Ascaris lumbricoides. Hal ini akan lebih memperkuat apakah keberadaan telur Ascaris lumbricoides pada kuku berhubungan dengan kejadian askariasis pada pengrajin batu bata.

\section{DAFTAR PUSTAKA}

1. Hotez PJ, Bundy DAP, Beegle K, Brooker S, Drake L, Silva ND, et al. Helminth Infections: Soil-transmitted helminth infections and schistosomiasis. In: Jamison DT, Breman JG, Measham AR, et.al, editors. Disease control priorities in developing countries. 2nd Ed. New York: Oxford University Press. 2006.

2. World Health Organization. Soiltransmitted helminthiases: eliminating soil-transmitted helminthiases as public health problem in children: Progress report 2001-2010 and strategic plan 2011-2020. 2012

3. Rahmadhini NS, Mutiara H. Pemeriksaan kuku sebagai pemeriksaan alternatif dalam mendiagnosis kecacingan. Jurnal Majority. 2015;1;4(9):113-117.

4. Maguire JH. Intestinal nematodes (roundworms). In: Mandell GL, Bennett JE, Dolin R. editors. In: Mandell, douglas, and bennett's principles and practice of infectious diseases. $7^{\text {th }} \mathrm{Ed}$. Philadelphia: Churchill Livingstone Elsevier. 2010.

5. Mulasari SA, Maani D. Hubungan antara kebiasaan penggunaan alat pelindung diri dan personal hygiene dengan kejadian infeksi kecacingan pada petugas sampah di kota yogyakarta. Jurnal Ekologi Kesehatan. 2013:12(2).

6. Nurfalaq DKF, Saleh I, Rochmawati. Hubungan karakteristik individu, sanitasi lingkungan rumah, personal hygiene, penggunaan apd dan lama bekerja dengan kejadian infestasi sth (studi pada petani di desa nusapati kecamatan sungai pinyuh kabupaten mempawah). 2016. Available from: URL: HIPERLINK: http://repository.unmuhpnk.ac.id/311/

7. Nurliana N, Setia L, Ayanti BP. Gambaran kontaminasi telur cacing nematoda usus dan personal hygiene pada peternak ayam di desa kuala kapuas maret 2018. akademi analis kesehatan borneo lestari, d3 teknologi laboratorium medik. 2018. Available from: URL: HIPERLINK:

http://repo.stikesborneolestari.ac.id/281/

8. Cheesebrough M. Medical laboratory manuals for tropical countries, microbiology and parasitology. Cambridge University Press. 2005;209235

9. Waqiah U. 2010. Hubungan hygiene perorangan dengan kejadian infeksi kecacingan pada pemulung anak usia sekolah dasar di tpa antang makassar. [Skripsi]. Makassar: Universitas Islam Negeri Alauddin Makassar.

10. Resnhaleksmana E. Prevalensi nematoda usus golongan soil transmitted helminthes (STH) pada peternak di lingkungan gatep kelurahan ampenan 
selatan. Media Bina Ilmiah. 2014;8(5): 45-50.

11. Tirtayanti NLGM, Widhya CD, Dhyanaputri IS. Identifikasi telur cacing nematoda usus pada kuku tangan pengrajin genteng di desa pejaten kediri tabanan. Meditory The Journal of Medical Laboratory. 2016;4(2): 109-116. Available from: URL: HIPERLINK: https://ejournal.poltekkesdenpasar.ac.id/index.php/M/article/view/ $52 / 23$.

12. Herdiansyah D, Santoso SS. Analisis kebersihan diri terhadap keberadaan telur cacing ascaris pada kuku nelayan desa batu karas cijulang pangandaran. Jurnal Kedokteran dan Kesehatan. 2019;15(1). Available from: URL: HIPERLINK: https://jurnal.umj.ac.id/index.php/JKK/art icle/view/3949/2984

13. Yuniarti M, Nurrahma IM, Ramadhani D. 2017. Gambaran telur cacing nematoda usus soil transmitted helminth (sth) pada kuku kuli pengangkut tanah di rt. 10 rw. 04 kelurahan sungai tiung kecamatan cempaka kota banjarbaru. [Tugas Akhir]. Kalimantan Sekatan: Akademi Analis Kesehatan Borneo Lestari. Available from: URL: HIPERLINK: http://repo.stikesborneolestari.ac.id/104/1 /Artikel\%20Ilmiah.pdf.

14. Wuriani NKA. 2019. Identifikasi telur cacing sth (soil transmitted helminth) pada kuku tangan pengrajin batu bata di banjar pande, desa tulikup, gianyar. [Tugas Akhir]. Denpasar: Politeknik Kesehatan Kemenkes Denpasar.

15. Desiyanti D. 2017. Gambaran telur soil transmitted helminths pada kuku pembuat batu bata di pinggiran aliran sungai citarum semarang. [Tugas Akhir]. Semarang: Poltekkes Kemenkes Semarang.

16. Nurhayani, Wijayanti Y, Indriyanti DR. The affecting factors occurring of worms in roof tile and bricks craftsmen in boyolali. Public Health Perspectives Journal.4(2);2019: 122-128.
17. Nurjana MA, Sumolang PPF, Chadijah S, Veridiana NY. Faktor risiko infeksi ascaris lumbricoides pada anak sekolah dasar di kota palu. Jurnal vektor penyakit. 7(1);2013: 23-29

18. Arif MI. 2017. Faktor risiko terjadinya infeksi kecacingan (ascaris lumbricoides dan trichuris trichiura) pada anak sekolah dasar di kelurahan pannampu kec. tallo kotamadya makassar. [Tesis]. Surabaya: Universitas Airlangga

19. Eryani D, Fitriangga A, Kahtan MI. Hubungan personal hygiene dengan kontaminasi telur soil transmitted helminths pada kuku dan tangan siswa sdn 07 mempawah hilir kabupaten pontianak. Jurnal Pendidikan Dokter Kalbar. 3(1);2015: 1-19

20. Yamistada G, Sari JN. Analisis hygiene perorangan terhadap kontaminasi telur cacing pada kuku siswa sekolah dasar di wilayah puskesmas tahtul yaman kota jambi. Jurnal Bahana Kesehatan Masyarakat (Bahana of Journal Public Health). 2017;1(2): 106-113.

21. Risnawati G. Faktor perilaku cuci tangan pakai sabun (ctps) pada masyarakat di tanah kalikedinding. Jurnal Promkes. 2016;4(1): 70-81.

22. Halleyantoro R, Riansari A, Dewi DP. Insidensi dan analisis faktor risiko infeksi cacing tambang pada siswa sekolah dasar di grobogan, jawa tengah. Jurnal Kedokteran Raflesia. 2019;5(1): 18-27. 